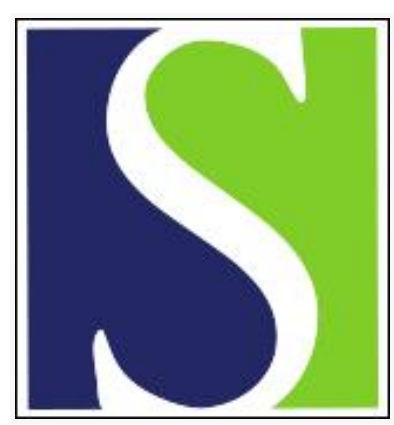

Scand J Work Environ Health 1993;19(4):277-283

https://doi.org/10.5271/sjweh.1473

Issue date: 01 Aug 1993

Development of trapezius myalgia among female workers performing light manual work.

by Veiersted KB, Westgaard RH

Affiliation: National Institute of Occupational Health, Department of Physiology, Oslo, Norway.

The following article refers to this text: 2013;39(4):390-400

This article in PubMed: www.ncbi.nlm.nih.gov/pubmed/8235517 


\title{
Development of trapezius myalgia among female workers performing light manual work
}

\author{
by Kaj Bo Veiersted, MD, ${ }^{1}$ Rolf $\mathrm{H}$ Westgaard, $\mathrm{PhD}^{2}$

\begin{abstract}
VEIERSTED KB, WESTGAARD RH. Development of trapezius myalgia among female workers performing light manual work. Scand J Work Environ Health 1993;19:277-83. The aim of this prospective study was to detect a possible development of trapezius myalgia likely to be work-related in initially healthy female packers. Symptoms were recorded on a five-step intensity scale in a daily diary and in an interview at ten-week intervals. All of the subjects were interviewed concerning assumed risk factors during work and leisure time, and a clinical examination was performed. Within their first year of employment, 17 of 30 subjects developed work-related trapezius myalgia of sufficient intensity to be classified as patients. The median time before a clinically confirmed patient status was 23 (range 6-51) weeks. The symptoms showed a fluctuating pattern, decreasing on the weekends and during some holidays. In conclusion, likely work-related trapezius myalgia of a nonchronic character showed a high one-year cumulative incidence at a plant with repetitive light work.
\end{abstract}

Key terms: neck and shoulder disorders, pain diary, prospective design, repetitive work load.

Complaints of discomfort and pain in the neck and shoulder region are common in modern society and have been firmly associated with repetitive work tasks with static muscle activity (1-5). Information about the temporal development of these complaints has mainly been based on retrospective information and sick leave statistics. Maeda et al (6) reported two incidence peaks of occupational cervicobrachial disorder for keypunchers approximately 6 and 24 months after the start of employment. Studies on musculoskeletal sick leave for sewing machine operators and workers on an electromechanical assembly line showed an increase during the first two to three years of employment (7-9). These studies all concerned job exposure with high static muscular activity. It would be of value to know how these complaints developed, and which risk factors are important at a plant with exposure to low static load.

A prospective study of 30 female workers at a chocolate manufacturing plant was carried out to address these questions. The relation of trapezius myalgia to work was examined, especially with the aid of vocational muscle activity evaluated by electromyography (10) and subjectively assessed risk factors of the job and leisure time (11). The purpose of this study was (i) to evaluate a possible development of trapezius myalgia at a plant with repetitive light work and, if it was found, (ii) to analyze its time

1 National Institute of Occupational Health, Department of Physiology and Department of Occupational Health, Oslo, Norway.

2 The Norwegian Institute of Technology, Division of Organization and Work Science, Trondheim, Norway.

Reprint requests to: Dr KB Veiersted, National Institute of Occupational Health, PO Box 8149 Dep, N-0033 Oslo, Norway. course in relation to employment time and onset of patient status, as well as its time course during the week and the year.

\section{Subjects and methods}

\section{Subjects and patient status}

Fifty-five women hired consecutively by a chocolate manufacturing plant were included in the study from the start of their employment. Three subjects declined to participate, and the other 52 signed an informed consent form. The study was approved by the regional ethical committee. To comply with the inclusion criteria, the subjects were not allowed to (i) have been working in the same or a similar factory during the last five years, (ii) suffer from either a systemic illness (rheumatologic, vascular, or malignant disease) or a local neck or shoulder disorder (malformation, neurological or traumatic), and (iii) have had a medical consultation due to neck or shoulder pain during the year preceding this employment.

The subjects were included during a two-year period from August 1987 to August 1989, and data were collected until late January 1990 . The distribution of observation time and the cause of termination are shown in figure 1 . The longest participation time was 120 weeks.

Information on complaints of discomfort and pain in the neck and shoulders was collected through a daily pain diary and interviews every 10 th week. A five-point pain scale (12) and the anatomic regions (13) shown in figure 2 were used. The cohort was divided into patients and nonpatients after termination of the study according to the degree of symptoms and signs of trapezius myalgia. The following four criteria had to be met for patient status: (i) a 
minimum observation time of six months (also for nonpatients), (ii) at least one 10 -week period with a maximum complaint score of 3 or 4 , including two weeks with a continuous score of 2 or higher, (iii) one or more tender or trigger points in the trapezius muscle, and (iv) symptoms with no known causation outside work. Figure 3 illustrates the complaint development of a single patient based on her diary recordings. She was given patient status in the 20 th week of employment with a subsequent sick leave between week 21 and 24. Note the reporting of initial slight complaints for both shoulders and the neck in the figure.

The agreement between the daily reports of complaints and the information given in the interview every 10 th week was determined. The maximal complaint level reported in the diary for the neck and the right and left shoulder was compared with the cor-

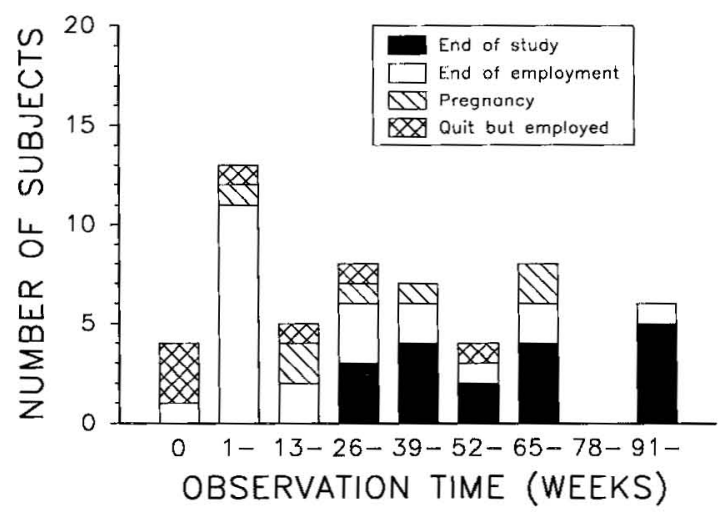

Figure 1. Distribution of observation times and the cause of termination for all of the subjects initially included in the study (55 subjects). responding anamnestic information from the interview. A data set was included if at least $70 \%$ of the time covered by the interview (last 10 weeks) was recorded in the diary reports. The first 10 -week period was excluded due to possible postexercise muscle soreness. A Pearson correlation test between the two recording methods resulted in a coefficient of 0.87 , based on 190 data sets from 31 subjects ( 8 not from the 30 -subject cohort). No systematic differences were found when the three body regions and the 10 -week periods were considered separately. A McNemar test showed symmetry of the results $(\mathrm{P}=0.3), 77 \%$ with identical assessments, $16 \%$ with one level, $6 \%$ with two levels, and $1 \%$ with three levels of difference. The test of "validity" gave a kappa value of 0.67 , indicating good agreement $[14,15$ (program 4F)].

Thirty subjects without symptoms related to known factors outside work and employed for more than six months constituted the cohort study base. The 22 subjects not included in the cohort had the same mean level of complaints during their employment and a similar pattern for vocational muscle activity as the cohort (10). The mean age was the same (25.5 years).

If a subject terminated her job before the end of the study, an interview was performed that included questions about neck and shoulder pain and the cause of termination (figure 1). A group of seven subjects refused to participate ("quit but employed"), six subjects became pregnant and left the study, and a large group ( 23 subjects) terminated their employment before the end of the study mainly because they preferred another job. Nineteen subjects were observed from the beginning of employment to the end of the study. No significant difference in the electromyographic parameters, development of complaints, or

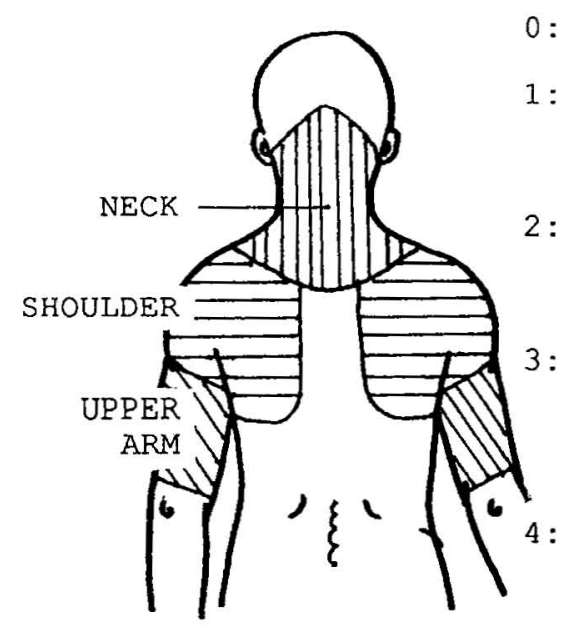

0: No complaints.

1: Almost no complaints, only slight feeling of discomfort at breaks when not concentrating on the work tasks.

: Slight complaints when performing the work tasks, but not interfering with job performance.

Complaints during work, making it necessary to maintain a conscious effort in order to carry out the work tasks. Need for breaks.

It is difficult to carry out work because of the complaints. The feeling of discomfort is not fully relieved during a break.

Figure 2. Assessment of the intensity of discomfort or pain complaints in the neck and shoulders on a five-point scale. One of the alternatives had to be chosen. The anatomic regions also included the upper arm, not used for the complaint score but for controlling for referred pain. 
occurrence of patient status were found between the different groups mentioned. The turnover in the investigated departments was similar to that of the rest of the plant (in parentheses): 1987: 29\% (31\%), 1988: $17 \%$ (18\%), and 1989: $11 \%(10 \%)$.

\section{Work load exposure}

The subjects were employed full-time, $5 \mathrm{~d}$ a week, $61 \%$ during the day ( $8 \mathrm{~h} / \mathrm{shift}$ ) and $39 \%$ in the evening $(7.5 \mathrm{~h} / \mathrm{shift})$, all on a fixed wage system. The subjects had the following three vacation or holiday periods per year: summer (4 weeks), Christmas ( 1 week), and Easter ( 1 week). Work at two different categories of machines, for production and packing, were included in the study. In both categories the following three tasks were performed: feeding the machine, controlling and packing the products, and, finally, collecting finished products for further distribution (10). Work rotation, alternating between tasks every $15-30 \mathrm{~min}$, was performed at all of the machines. The work was mainly machine-paced, with no individual influence on speed or on the organization of the work.

\section{Procedure}

The new employees were asked to join the study within a month after the first day at work. Structured interviews were performed every 10th week in an undisturbed room during workhours. Complaints of discomfort or pain in the neck and shoulders during the last 10 weeks were recorded. Neither the interviewer nor the subject was allowed to check diaries for this information. The clinical examination was performed with the subject seated in a comfortable chair with her arms in her lap. Symmetrical flat onefinger palpation of the trapezius muscles was done in search for 16 bilaterally situated tender or trigger points according to Travell \& Simons (16). The interview and examination lasted about $30 \mathrm{~min}$. The same physician (KBV) performed all of the interviews and clinical examinations. The examination was followed by the collection of the pain diary forms for the preceding 10 weeks, and the subject was given new forms for the next 10 weeks. No economic reward was given for the completed forms. The number of subjects returning pain diaries diminished considerably after the first 30 weeks of the observation period and was low after the first year of employment. The diagnosis of trapezius myalgia was made either by the first author (KBV) on the basis of the interview and physical examination or by a physician outside the plant. In the latter case the diagnosis was confirmed by a telephone call.

\section{Statistical methods}

Medians, percentiles, and ranges were used in the description of the data, if nothing else is noted. Nonparametric statistics were used to test the differences

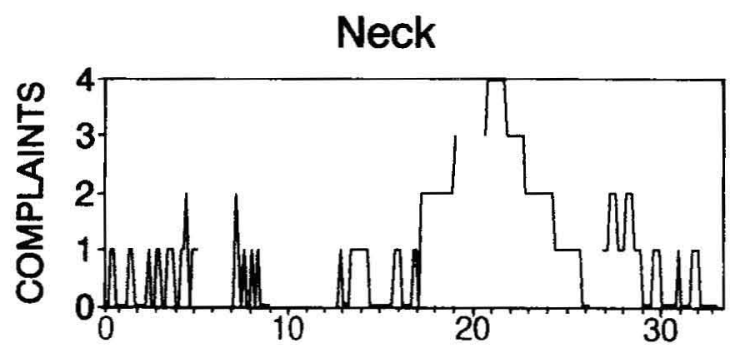

Right Shoulder

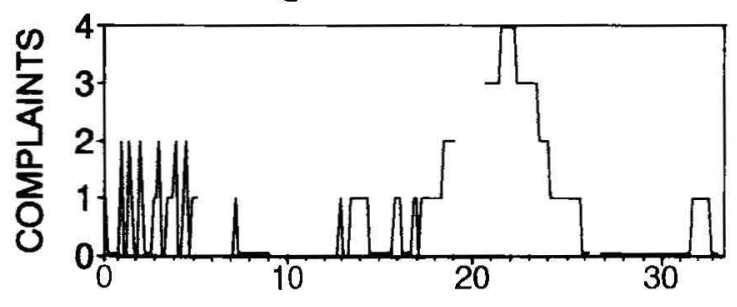

Left Shoulder

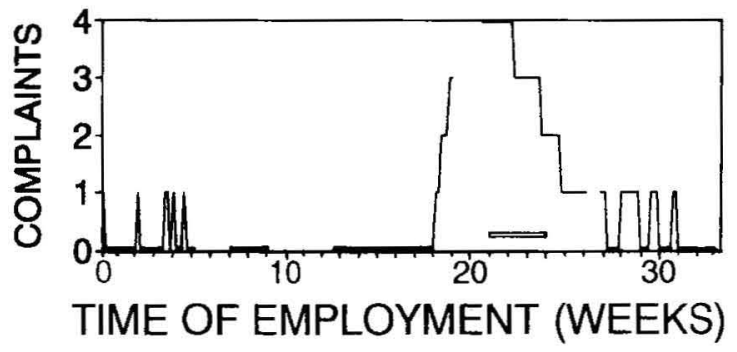

Figure 3. Example of complaint development in the neck and shoulders of one patient, reported in the pain diary. The hollow bar indicates a three-week sick leave. The thin bottom lines show periods with missing data.

in mean values in univariate analyses. The MannWhitney test, the chi-squared test, and the Wilcoxon signed-ranks test for paired samples were used, depending on the data format and the hypothesis being tested (17). Wald-type chi-squared statistics were used in the unbalanced repeated-measures models for the analysis of variance in the development of complaints during the week [15 (program 5V)]. The statistical significance was given by two-tailed P-values of less than 0.05 .

\section{Results}

\section{Patients and nonpatients}

Seventeen of 30 subjects complied with the criteria of patient status at least once during the first year of employment (figure 4). Four patients who improved after experiencing symptoms in the beginning of employment met the criteria again towards the end of the first year. The median time to patient status was 23 (range 6-51) weeks. In the interview all of the patients reported complaints of at least level 


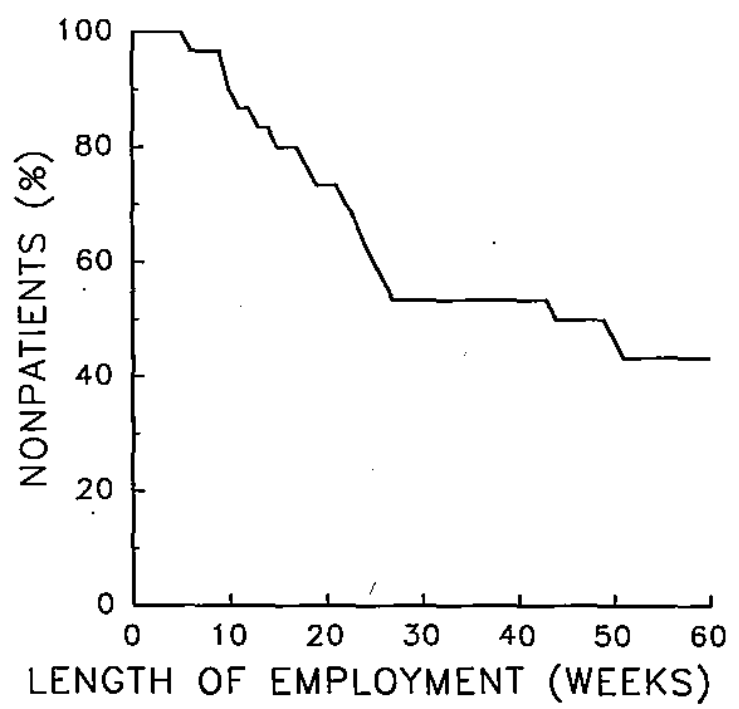

Figure 4. Frequency of nonpatients during the first year of employment. The first time the subject met the criteria for patient status was used as the "time to event."

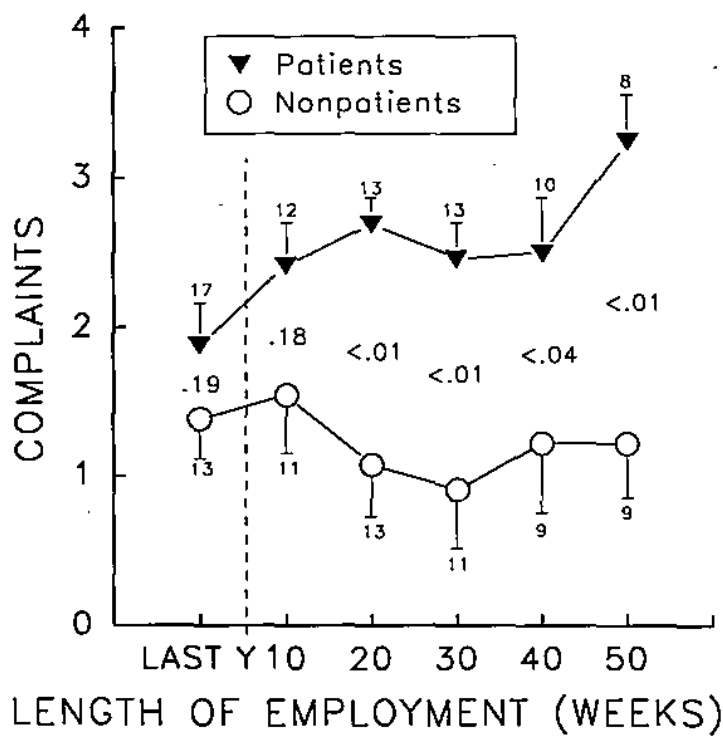

Figure 5. Development of complaints for patients ( $\boldsymbol{\nabla})$ and nonpatients $(\mathrm{O})$ during the first year of employment. Maximum complaint level of the neck or shoulders during the preceding 10 weeks or preceding year ( = last y) before employment as reported in the interview. P-values for Mann-Whitney tests, bars indicating the standard errors, and the number of subjects behind each mean value are shown.

3 for two or more 10-week periods. They had at least two tender or trigger points in the trapezius muscles, but this was also the case for 8 of 13 nonpatients one or two times during the observation period. The mean number of tender or trigger points in the patients at the time they received patient status was 3.8 (range
2-6); this value was significantly higher than for the nonpatients' mean value for the first year of employment (1.1 points with a range of $0-4$ ). The nonpatient group $(\mathrm{N}=13)$ stayed at a mean level of "almost no complaints..." throughout the study (figure 5). There was no difference in complaints the last year before employment, nor during the first 10 weeks of employment. Thereafter the neck and shoulder complaints of the patient group increased gradually, and maintained a significantly higher leve! than for the nonpatient group. Three nonpatients had one short episode with pain at level 3 , but with no continuous complaints at level 2 or higher for a twoweek period.

Nine of the 17 patients recorded a sick leave prescribed by a physician. The median duration of sick leaves due to neck or shoulder disorders was 2 (range 1-15) weeks. The other patients (eight subjects) had a similar level and time course of musculoskeletal complaints, but no sick leave. There were no significant differences between the patients with and those without sick leave concerning the time from start of employment to patient status [26 (range 9--51) weeks for those with sick leave and 19 (range 644) weeks for those without sick leave]. Neither palpable tender or trigger points distinguished between those with and those without sick leave [3.1 (range $2-5$ ) versus 4.5 (range $2-6$ )].

\section{Time course of complaints}

The diaries indicated a gradual increase of complaints during the month preceding patient status (figure 6). The symptoms persisted at a mean level of about two for the next six months. The development of complaints throughout the week (figure 7) showed a slight but significant increase during the first $5 \mathrm{~d}$ of the week when the data of all the subjects in the cohort were pooled $(P<0.03)$.

Table 1 gives the complaint level according to the time of the week or the year, and also the total complaint level, for the patients and nonpatients. Each subject contributed with a mean complaint level for weekdays, weekends, autumn (all days from the summer vacation to the Christmas holiday) and spring (all days from the Christmas holiday to the summer vacation). The complaint level during weekends was significantly lower than during the workdays for both groups. No difference was found between spring and autumn. The mean complaint level before and after the holiday period or vacation was calculated on the basis of four-week periods, and it showed a significant reduction after the Christmas holiday for the patient group. The complaint level was reduced by two-thirds for the patients and about one-half for the nonpatients during the summer vacation (not significant - due to the small number of respondents after the summer vacation). 


\section{Discussion}

This prospective study showed a high one-year cumulative incidence of likely work-related trapezius myalgia at a plant with repetitive light work. Complaints of discomfort and pain in the neck and shoulders increased during the week and declined during weekends and some holidays.

\section{Study validity and patient definition}

The number of subjects included was small and therefore resulted in low power for the study. It may have been possible to augment the cohort study base by an extension of the two and a half years of study, but probably only to a limited extent due to the decreasing turnover rate at the plant.

Complaints from the neck and shoulders were reported in two ways. If the diary is considered the best approximation, the validity of the 10 -week interview was good. The diary itself showed poor compliance, with a low and rapidly decreasing number of respondents. A solution would possibly have been an economic reward for the delivery of finished forms. All of the patients reported considerably more symptoms and signs than necessary to fulfill the criteria for patient status, and thereby contrasted with the nonpatients. The patients had more tender and trigger points, but, in agreement with Sola \& Williams (18), muscle tenderness at palpation seemed not to be a good criterion for patient status, as this complaint was also reported by many nonpatients. Fifty-seven percent of the cohort contracted possible work-related trapezius myalgia within the first year of employment. This figure was a cumulative incidence for one year in a cohort of initially healthy subjects (ie, with few complaints during the year preceding the employment). Comparable data were difficult to find, but cross-sectional $(3,5,7,19)$, as well as follow-up $(20,21)$, studies suggest less frequent

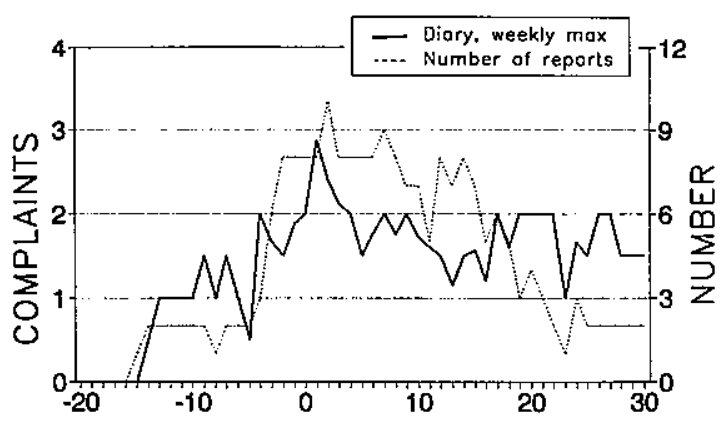

TIME AFTER PATIENT STATUS (WEEKS)

Figure 6. Complaint development to the time of and after patient status. Dark line shows the weekly maximum (max) diary report.

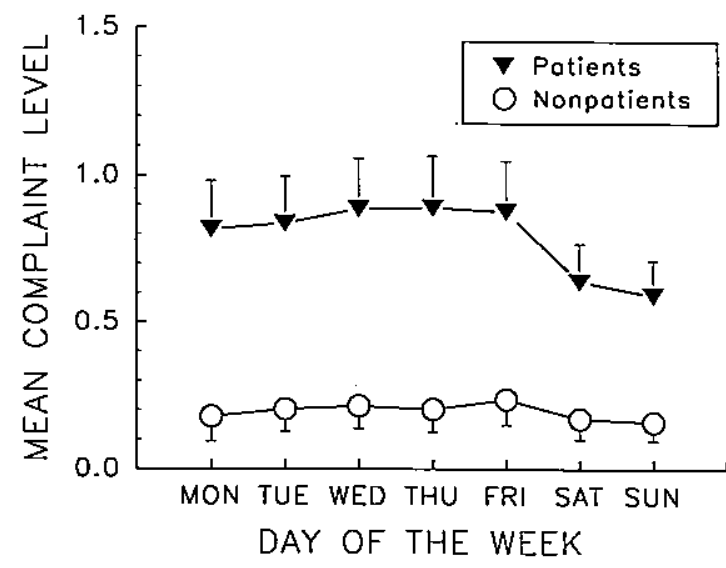

Figure 7. Complaint development through the week for patients $(N=11)$ and nonpatients $(N=12)$. Each subject contributed with the mean of all her reports on each day of the week, for patients also before contracting patient status. The standard errors are indicated by bars.

Table 1. Percentiles of complaint levels recorded in a daily diary for different periods.

\begin{tabular}{|c|c|c|c|c|c|c|c|c|c|c|}
\hline \multirow[b]{4}{*}{$\begin{array}{l}\text { Weekdays } \\
\text { Weekends }\end{array}$} & \multicolumn{5}{|c|}{ Patients } & \multicolumn{5}{|c|}{ Nonpatients } \\
\hline & \multicolumn{3}{|c|}{ Percentiles } & \multirow{2}{*}{$\begin{array}{c}\text { Number } \\
\text { of } \\
\text { subjects }\end{array}$} & \multirow{2}{*}{$P$-value ${ }^{a}$} & \multicolumn{3}{|c|}{ Percentiles } & \multirow{2}{*}{$\begin{array}{c}\text { Number } \\
\text { of } \\
\text { subjects }\end{array}$} & \multirow{2}{*}{ P-value ${ }^{a}$} \\
\hline & 25 & 50 & 75 & & & 25 & 50 & 75 & & \\
\hline & $\begin{array}{l}0.3 \\
0.1\end{array}$ & $\begin{array}{l}0.89 \\
0.74\end{array}$ & $\begin{array}{l}1.31 \\
0.98\end{array}$ & $\left.\begin{array}{l}11 \\
11\end{array}\right\}$ & $<0.01$ & $\begin{array}{l}0.02 \\
0.02\end{array}$ & $\begin{array}{l}0.07 \\
0.03\end{array}$ & $\begin{array}{l}0.37 \\
0.33\end{array}$ & $\left.\begin{array}{l}12 \\
12\end{array}\right\}$ & $<0.03$ \\
\hline $\begin{array}{l}\text { Autumn } \\
\text { Spring }\end{array}$ & $\begin{array}{l}0.24 \\
0.04\end{array}$ & $\begin{array}{l}0.63 \\
0.59\end{array}$ & $\begin{array}{l}1.21 \\
1.35\end{array}$ & $\left.\begin{array}{r}9 \\
11\end{array}\right\}$ & 0.68 & $\begin{array}{l}0.04 \\
0\end{array}$ & $\begin{array}{l}0.07 \\
0.02\end{array}$ & $\begin{array}{l}0.31 \\
0.28\end{array}$ & $\left.\begin{array}{l}12 \\
11\end{array}\right\}$ & 0.64 \\
\hline $\begin{array}{l}\text { Before summer } \\
\text { After summer }\end{array}$ & $\begin{array}{l}0.04 \\
0\end{array}$ & $\begin{array}{l}0.37 \\
0.14\end{array}$ & $\begin{array}{l}1.18 \\
0.39\end{array}$ & $\left.\begin{array}{l}7 \\
3\end{array}\right\}$ & 0.11 & $\begin{array}{l}0 \\
0\end{array}$ & $\begin{array}{l}0.02 \\
0.03\end{array}$ & $\begin{array}{l}0.25 \\
0.11\end{array}$ & $\left.\begin{array}{l}8 \\
9\end{array}\right\}$ & 0.87 \\
\hline $\begin{array}{l}\text { Before Christmas } \\
\text { After Christmas }\end{array}$ & $\begin{array}{l}0.15 \\
0\end{array}$ & $\begin{array}{l}0.80 \\
0.17\end{array}$ & $\begin{array}{l}1.44 \\
0.78\end{array}$ & $\left.\begin{array}{l}9 \\
9\end{array}\right\}$ & $<0.02$ & $\begin{array}{l}0 \\
0\end{array}$ & $\begin{array}{l}0 \\
0\end{array}$ & $\begin{array}{l}0.22 \\
0.28\end{array}$ & $\left.\begin{array}{l}9 \\
8\end{array}\right\}$ & 1.0 \\
\hline $\begin{array}{l}\text { Before Easter } \\
\text { After Easter }\end{array}$ & $\begin{array}{l}0.06 \\
0.01\end{array}$ & $\begin{array}{l}0.59 \\
0.66\end{array}$ & $\begin{array}{l}1.36 \\
1.46\end{array}$ & $\left.\begin{array}{l}8 \\
8\end{array}\right\}$ & 0.87 & $\begin{array}{l}0 \\
0\end{array}$ & $\begin{array}{l}0 \\
0\end{array}$ & $\begin{array}{l}0.35 \\
0.35\end{array}$ & $\left.\begin{array}{l}9 \\
9\end{array}\right\}$ & 0.59 \\
\hline Total mean & 0.25 & 0.85 & 1.2 & 11 & - & 0.02 & 0.06 & 0.36 & 12 & - \\
\hline
\end{tabular}

a Wilcoxon signed-ranks test for paired samples. 
occurrence of neck and shoulder complaints. Explanations for this discrepancy could be that our patient definition also included sufferers without sick leave and that other studies have been based on populations with more prolonged experience in their present job, thus potentially being a selected population. The new employees were frequently young and inexperienced and therefore possibly more vulnerable to musculoskeletal disorders than elderly persons (1), as has also been shown for back injuries (22).

\section{Time course of complaints}

Only a few studies have used a prospective design to describe the development of neck and shoulder complaints. Takala et al (21) studied the development of complaints in a workplace with light sedentary work. Female bank cashiers responded to a postal questionnaire four times at three-month intervals. These responses disclosed a fluctuating occurrence of nonsevere complaints, with a higher frequency during the autumn and winter. Our study also showed a fluctuating pattern, but could not identify any significant seasonal changes, except for reduced complaints after some holidays. A clear alleviation of the complaints during the weekends, followed by a weak increasing trend during the weekdays, indicated that the complaints were not chronic. Kilbom \& Persson (23) reported an increase in severe musculoskeletal disorders among workers in an electronics manufacturing plant; from 8 to 18 and $21 \%$ after one and two years of follow-up, respectively. In a study with a similar design, Hägg \& Suurküla (24) found an increase in severe symptoms, especially during the first year of the observation time. These studies were all based on work tasks with high static muscular load. Our study indicates that many new cases of nonchronic trapezius myalgia occur during the first year of employment, especially during the first six months, in a job with low static load.

\section{Work-related etiology}

Studies of work-related musculoskeletal disorders for packing in the food processing industry are rare, and the few existing studies show contradicting results. Luopajärvi et al (3) found that the repetitive work load of assembly-line packers did not incur any significant increased risk of tension neck syndrome when compared with the more dynamic work of shop assistants. Nevertheless, some indications of a high prevalence of disease for packers have been reported (19). Our attempt to include only assumed work-related trapezius myalgia contracted at the current plant was based on three conditions. First, only subjects with no medical consultation due to neck or shoulder pain the year preceding employment were included, and no significant difference was found in complaint level between future patients and nonpatients during that year. Second, the duration of the exposure in the present job was plausible with regard to the initiation or facilitation of nonchronic symptoms $(6,9)$. Third, the relation between symptoms and work was built on several pieces of information from the subject, mainly the absence of competitive risk factors (11). Nevertheless, the relative risk for trapezius myalgia is impossible to establish in a study such as ours, since no reference group was used. The static muscular load of the work in this plant was very low (10). Consequently, work-related risk factors should probably be searched for in the temporal pattern of muscular activity at work. A crucial factor could be long sustained periods of (even low) activity caused by workplace design or psychogenetic tension due to psychosocial factors.

\section{Acknowledgments}

This project was supported by grants from the Norwegian Science and Engineering Council and from A/S Freia.

We are grateful to Professor $\mathrm{P}$ Andersen for his scientific advice and to Ms M Bull, Ms B Jarmark and Ms JT Stuenæs for their technical assistance.

\section{References}

I. Herberts P, Kadefors R, Andersson G, Petersén I. Shoulder pain in industry: an epidemiological study on welders. Acta Orthop Scand 1981;52:299-306.

2. Onishi N, Nomura H, Sakai K, Yamamoto T, Hirayama K, Itani T. Shoulder muscle tenderness and physical features of female industrial workers. J Hum Ergol 1976;5:87-102.

3. Luopajärvi T, Kuorinka I, Virolainen M, Holmberg M. Prevalence of tenosynovitis and other injuries of the upper extremities in repetitive work. Scand J Work Environ Health 1979;5 suppl 3:48-55.

4. Hagberg M, Wegman DH. Prevalence rates and odds ratios of shoulder-neck diseases in different occupational groups. Br J Ind Med 1987;44:602-10.

5. Ohlsson K, Attewell R, Skerfving S. Self-reported symptoms in the neck and upper limbs of female assembly workers: impact of length of employment, work pace, and selection. Scand J Work Environ Health 1989;15:75-80.

6. Maeda K, Hiroguchi S, Hosakawa M. History of the studies on occupational cervicobrachial disorder in Japan and remaining problems. J Hum Ergol 1982; 11:17-29.

7. Westgaard RH, Wærsted M, Jansen T, Aarås A. Muscle load and illness associated with constrained body postures. In: Corlett N, Wilson J, Manenica I, ed. The ergonomics of working posture. London: Taylor \& Francis, 1986:5-18.

8. Aarås A, Westgaard RH. Further studies of postural load and musculo-skeletal injuries of workers at an electro-mechanical assembly plant. Appl Ergon 1987; 18:211-9.

9. Wersted M, Westgaard RH. Working hours as a risk factor in the development of musculoskeletal complaints. Ergonomics 1991;34:265-76.

10. Veiersted KB, Westgaard RH, Andersen P. Electromyographic evaluation of muscular work pattern as a predictor of trapezius myalgia. Scand J Work Environ Health 1993;19:284-90.

11. Veiersted KB, Westgaard RH. Work-related risk fac- 
tors for trapezius myalgia. In: Hagberg M, Kilbom A, ed. International scientific conference on prevention of work-related musculoskeletal disorders PREMUS: book of abstracts, Sweden, 12-14 May 1992. Stockholm: Arbetarskyddsverket, 1992:307-9. (Arbete och hälsa; no 17.)

12. Westgaard RH, Jansen T. Individual and work-related factors associated with symptoms of musculoskeletal complaints: I. a quantitative registration system. Br J Ind Med 1992;49:147-53.

13 Kuorinka I, Jonsson B, Kilbom А, Vinterberg H, Biering-Sørensen F, Andersson G, et al. Standardised Nordic questionnaires for the analysis of musculoskeletal symptoms. Appl Ergon 1987;18:233-7.

14. Fleiss JL. The measurement of interrater agreement. In: Statistical methods for rates and proportion. New York, NY: John Wiley \& Sons, 1981:211-37.

15. Dixon WJ. Biological and medical data package: statistical software manual. Berkeley, CA: University of California Press, 1990.

16. Travell JG, Simons DG. Myofascial pain and dysfunction: the trigger point manual. London: Williams \& Wilkins, 1983.

17. Norusis MJ. SPSS/PC+ V2.0: base manual. Chicago, IL: Statistical Package for Social Sciences Inc, 1988.

18. Sola AE, Williams RL. Myofascial pain syndromes. Neurology 1956;6:91-5.

19. Ohara H, Nakagiri S, Itani T, Wake K, Aoyama H.
Occupational health hazards resulting from elevated work rate situations. J Hum Ergol 1976;5:173 - 82.

20. Kilbom $\AA$, Persson J, Jonsson B. Risk factors for workrelated disorders of the neck and shoulder - with special emphasis on working postures and movements. In: Corlett N, Wilson J, Manenica I, ed. The ergonomics of working posture. London: Taylor \& Francis, 1986: $44-53$.

21. Takala E-P, Viikari-Juntura E, Moneta GB, Saaremaa $\mathrm{K}$, Kaivanto K. Seasonal variation in neck and shoulder symptoms. Scand J Work Environ Health 1992; $18: 257-61$.

22. Bigos SJ, Spengler DM, Martin NA, Zeh J, Fisher L, Nachemson A. Back injuries in industry: a retrospective study: III. employee-related factors. Spine 1986; $11: 252-5$.

23. Kilbom $\AA$, Persson J. Work technique and its consequences for musculoskeletal disorders. Ergonomics 1987;30:273-9.

24. Hägg GM, Suurküla J. Zero crossing rate of electromyograms during occupational work and endurance tests as predictors for work related myalgia in the shoulder/neck region. Eur J Appl Physiol 1991;62: $436-44$.

Received for publication: 2 December 1992 